\title{
Atypical Ductal Lesion in the Breast: Review
}

\author{
Shinya Tajima ${ }^{1 *}$, Ichiro Maeda ${ }^{1}$, Motohiro Chosokabe ${ }^{1}$, Masayuki Takagi ${ }^{1}$, Saeko Naruki ${ }^{1}$, Akira Endo ${ }^{1}$, \\ Yasushi Ariizumi ${ }^{1}$, Masatomo Doi ${ }^{1}$, Keiko Kishimoto ${ }^{2}$ and Koichiro Tsugawa ${ }^{3}$ \\ ${ }^{1}$ Department of Pathology, St. Marianna University School of Medicine, Japan \\ ${ }^{2}$ Department of Radiology, St. Marianna University School of Medicine, Japan \\ ${ }^{3}$ Department of Breast and Endocrine Surgery, St. Marianna University School of Medicine, Japan
}

*Corresponding author: Shinya Tajima, Department of Pathology, St. Marianna University School of Medicine, Kawasaki City, Japan.

Received Date: February 01, 2019

Published Date: February 13, 2019

\section{Review}

Atypical ductal lesions of the breast are considered mainly "Atypical ductal hyperplasia (ADH)" ADH is defined as intraductal feature of architectural atypia [1]. However, diagnosis of $\mathrm{ADH}$ is challenging, because the interpretation of diagnosing ADH is different and vary between diagnostic pathologists. Goi S [2] advocated two pattern theory in the breast [2]. First, true borderline malignancy lesions are existed in the breast. Second, true borderline malignancy lesions are not existed, because borderline malignancy lesions which was thought at a glance are not true borderline lesions but pathologists cannot divide between malignant and benign because of their incapable. Goi S. thought that the latter theory was appropriate. Furthermore, he also thought that benign and malignant should be rigidly separated, and the most important thing is to reduce overdiagnosis or underdiagnosis. However, our recent study indicates the existence of the true borderline lesion. After paragraph, I will write this matter in detail. In addition, ADH is not clearly understood whether borderline malignancy or not, and that is still wrapped mysteriously.

In this paragraph, we will depict about the characteristics of $\mathrm{ADH}$. The definitions of $\mathrm{ADH}$ are clonal intraductal proliferation with architectural and cytologic features approaching those seen in low-grade ductal carcinoma in situ [3]. ADH is a marker of increased risk for developing invasive carcinoma and a non-obligate precursor of carcinoma. And ADH is thought to be contain both usual ductal hyperplasia and low-grade ductal carcinoma in situ. This criterion might have difficulty in diagnosing $\mathrm{ADH}$. ADH typically present as a single focus or involves a small area, and $\mathrm{ADH}$ and Ductal carcinoma in situ are often found in close area. So, ADH on core needle biopsy is an indication for excision. In immunohistochemically, ADH demonstrates generally negative for high molecular weight cytokeratin of CK5/6, and typically diffuse high level positive for estrogen receptor (ER). This type of immunostaining pattern is similar to ductal carcinoma in situ. Discrimination between ADH and ductal carcinoma in situ is also difficult in immunostaining pattern. Moreover, DNA studies also show genetic similarity between ADH and low-grade ductal carcinoma in situ. ADH, low-grade ductal carcinoma in situ, and low-grade invasive ductal carcinoma have similar gene expression pattern. However, differences are in quantitative levels of expression. Hence, to differentiate between ADH and low-grade ductal carcinoma in situ is difficult only HE section.

In this paragraph, we will discuss about breast papillary lesion which is important as well as ADH. Because understanding of the concept of breast borderline malignancy, breast papillary lesion is also important. To differentiate between benign and malignant lesion in breast papillary lesion, it is reported that combination of high molecular weight cytokeratin (HWCK) of CK14 and estrogen (ER) immunostainings are useful [4]. In using these immunostainings, almost all of the papillary lesions are diagnosed benign or malignant excluding apocrine papillary lesion. Furuya $\mathrm{C}$, et al. [5] advocated the Differential Index using Allred Score: ([ER total score] + [MUC3 total score]) / ([CK5/6 total score] + [p63 total score]) [5]. If this score is less than 1 , it is thought that it is benign lesion. This formula is useful discriminating between benign and malignant papillary lesions, if CK14 and ER are not available. MUC3 immunostaining is thought to be useful and important when diagnosing the difficult breast papillary lesion.

In this paragraph, we will discuss whether breast borderline malignancy lesions are existed or not by the viewpoint of our cases and knowledge. Loss of myoepithelial cells in breast tumours are commonly thought to be malignant and invasive lesions. In the past, Tramm T, et al. [6] Cserni G, et al. [7] reported that benign and non-invasive apocrine papillary lesions which show reduction and occasional complete loss of myoepithelial cells [6,7]. These lesions are thought to be benign lesion, however lack of myoepithelial cells. And apocrine papillary lesions are considered to be distinct lesions. 
Recently, Shinya T, et al. [8] reported that the two cases of "Nonapocrine papillary lesions lacking myoepithelial cells" [8]. These lesions showed epithelial papillary proliferation with nuclear inverse polarity, absence of nuclear atypia lined by the fibrovascular core, and lack of myoepithelial cells. In immunostainings, CK14 and ER were both negative. Hence, they tried the differential index, and the lesions were considered to be at the most a tumour of uncertain malignant potential. Someone indicate these breast lesions' name is too long, so, "Tajioma" might be appropriate. Then, taking into consideration of these things, it might be thought that there is the breast papillary lesion between non-invasive and invasive lesion. This ambiguous status might reflect the existence of breast borderline malignancy. We think breast borderline malignancy might exist as well as ADH. In the future, the report of breast lesions lacking myoepithelial cells which behave as benign to borderline malignancy may be increase.

In conclusion, diagnostic interpretation of $\mathrm{ADH}$ is thought to be wide range and vary. Because of this, ADH is challenging, interesting and fascinating. And, whether true borderline ADH is existed or not is in controversial. However, breast borderline papillary lesion might be suggested because of our study cases. We have to diagnose the breast papillary lesion as well as $\mathrm{ADH}$ attentively.

\section{Acknowledgement}

None.

\section{Conflict of Interest}

No conflict of interest.

\section{References}

1. PP Rosen et al. (2008) Ductal hyperplasia. In Rosen's Breast Pathology 9: $259-260$

2. Goi S (2001) Pathology of the breast. Japanese J Diagn Pathol 18(1): 1-5.

3. Hicks, Lester (2012) Atypical ductal hyperplasia. In Diagnostic Pathology Breast 4: 64-69.

4. Shinya T, Ichiro M, Motohiro C, Keiko K, Takafumi O, et al. (2018) Breast Benign Papillary Lesions: Mini-review. Clin Pathol and Res J 2(1): 1-2.

5. Furuya C, Kawano H, Yamanouchi T, Oga A, Ueda J, et al. (2012) Combined evaluation of CK5/6, ER, p63, and MUC3 for distinguishing breast intraductal papilloma from ductal carcinoma in situ. Pathol Int 62(6): 381-390.

6. Tramm T, Kim JY, Tavassoli FA (2011) Diminished number of complete loss of myoepithelial cells associated with metaplastic and neoplastic apocrine lesions of the breast. Am J Surg Pathol 35(2): 202-211.

7. Cserni $G$ (2008) Lack of myoepithelium in apocrine glands of the breast does not necessarily imply malignancy. Histopathology 52(2): 253-255.

8. Shinya T, Ichiro M, Yoshio, Kazama A, Koizumi HA, et al. (2018) Nuclear inverse polarity papillary lesions lacking myoepithelial cells: A report of two cases. Pathol Int 68(1): 36-40. 